\title{
Aortic Stiffness and Kidney Disease in an Elderly Population
}

\author{
Katherine H. Michener ${ }^{a}$ Gary F. Mitchell $^{\mathrm{b}}$ Farzad Noubary $^{\mathrm{c}}$ Naya Huang $^{\mathrm{a}}$ \\ Tamara Harris $^{d}$ Margret B. Andresdottire Runolfur Palsson ${ }^{e, f}$ \\ Vilmundur Gudnason ${ }^{\mathrm{f} g}$ Andrew S. Levey ${ }^{\mathrm{a}}$ \\ ${ }^{a}$ Division of Nephrology, Tufts Medical Center, Boston, Mass., ${ }^{b}$ Cardiovascular Engineering, Inc., Norwood, Mass., \\ 'The Institute for Clinical Research and Health Policy Studies, Tufts Medical Center, and Tufts Clinical and Translational \\ Science Institute, Tufts University, Boston, Mass., and d National Institute on Aging, Bethesda, MD, USA; ${ }^{e}$ Division of \\ Nephrology, Landspitali - The National University Hospital of Iceland, ${ }^{f}$ University of Iceland, Reykjavik, and ${ }^{9}$ Icelandic \\ Heart Association, Kopavogur, Iceland
}

\section{Key Words}

Albuminuria · Aortic stiffness - Chronic kidney disease .

Elderly $\cdot$ Glomerular filtration rate

\begin{abstract}
Background/Aims: The causes of chronic kidney disease (CKD) in older people are not well understood. Aortic stiffness increases with age and results in the transmission of increased pulsatility into the kidney microvasculature, potentially contributing to CKD in older populations. Methods: We utilized data from the Age, Gene/Environment, Susceptibility-Reykjavik Study, a community-based prospective cohort study of cardiovascular disease (CVD) in Iceland. The relationship of carotid pulse pressure (CPP) and carotid-femoral pulse wave velocity (CFPWV) with estimated glomerular filtration rate (eGFR) based on creatinine and cystatin $C$ and urine albumin-creatinine ratio (ACR) was assessed using linear regression, adjusting for demographics and CVD risk factors. Results: 940 participants (mean (SD) age 75.8 (4.7) years, mean (SD) CFPWV 12.9 (4.2) m/s, mean (SD) CPP 69 (21) $\mathrm{mm} \mathrm{Hg}$, mean (SD) eGFR 68 (16) $\mathrm{ml} / \mathrm{min} / 1.73 \mathrm{~m}^{2}$, and median (IQR) ACR 3 (2-6) $\mathrm{mg} / \mathrm{g}$ ) were included in this study. At CPP greater than $85 \mathrm{~mm} \mathrm{Hg}$, a higher CPP was associated with a lower eGFR in unadjusted analyses but not after adjust-
\end{abstract}

ment. CPP was significantly associated with a higher ACR in fully adjusted models $(\beta(95 \% \mathrm{Cl})=0.14(0.03,0.24) \mathrm{ln} \mathrm{mg} / \mathrm{g}$ per SD). Higher CFPWV was associated with lower eGFR and higher ACR in unadjusted analyses but not after adjustment. Conclusion: Greater aortic stiffness may be associated with modestly higher levels of albuminuria in the elderly. The association between aortic stiffness and lower eGFR may be confounded by age and CVD risk factors.

(c) 2015 National Institutes of Health (NIH) Published by S. Karger AG, Basel

\section{Introduction}

Chronic kidney disease (CKD) is a major public health concern that accounts for a large proportion of health care costs in the growing older segment of the population of western countries [1-4]. Despite the high prevalence of CKD in older adults, factors contributing to decline of kidney function with age are incompletely understood, and therapies for treatment or prevention are limited. A component of age-related changes in kidney structure and function may be caused by vascular disease [5-8]. Aortic stiffness, a structural and functional change in the central vasculature, has been shown to increase with age

\begin{tabular}{ll}
\hline KARGER 125/\% & $\begin{array}{l}\text { ○ 2015 National Institutes of Health (NIH) } \\
\text { Published by S. Karger AG, Basel } \\
0250-8095 / 15 / 0415-0320 \$ 39.50 / 0\end{array}$ \\
$\begin{array}{l}\text { E-Mail karger@karger.com } \\
\text { www.karger.com/ajn }\end{array}$ &
\end{tabular}

Andrew S. Levey, MD

Division of Nephrology, Department of Medicine Tufts Medical Center

800 Washington Street, Boston, MA 02111 (USA)

E-Mail alevey@tuftsmedicalcenter.org 
and this results in the transmission of higher pressure and flow pulsatility into the peripheral microvasculature [912]. The kidney is a high-flow and low-impedance organ, making it particularly vulnerable to hemodynamic changes in the central vasculature [13-29]. Hence, aortic stiffness may contribute to the pathophysiology of CKD in older individuals and may represent a target for interventions.

Increased aortic stiffness has been associated with kidney impairment and progression of CKD in prior studies. However, most previous studies that have been carried out in relatively small and highly selected samples, are not representative of the general elderly population, or did not use state-of-the-art measures of aortic stiffness and kidney function [14-29]. The Age Gene/Environment Susceptibility-Reykjavik Study (AGES-RS) is a population-based prospective cohort study in Iceland initially designed to explore cardiovascular disease (CVD) risk factors. In this study, we examined the link between kidney function and aortic stiffness in a large communitybased sample of older adults. We hypothesized that increased aortic stiffness would be associated with measures of CKD.

\section{Subjects and Methods}

\section{Study Population}

We utilized data from a substudy of the AGES-RS. Details of the study sample are provided elsewhere [30]. The Reykjavik Study was started in 1967 as a population-based prospective cohort study to examine cardiovascular risk factors and outcomes. People born between 1907 and 1935 and living in Reykjavik in 1967 were eligible for inclusion in the Reykjavik Study; a random sampling of the population yielded 30,795 participants. The AGES-RS began in 2002 as a follow-up to the Reykjavik Study to examine risk factors, genetic components, and gene-environment interactions for multiple diseases in older adults. The 5,764 participants in AGES-RS were randomly selected from the 11,549 survivors from the original Reykjavik Study participants. Of those 5,764 participants in AGES-RS-I, aortic tonometry had been performed in 1,082 people and so they were eligible for this study. Of those with tonometry performed, 940 had complete tonometry data and were included in this analysis (online suppl. fig. 1; for all online suppl. material, see www.karger.com/doi/10.1159/000431332).

\section{Aortic Stiffness Measures}

Participants were studied in the supine position after $10 \mathrm{~min}$ of rest. Auscultatory blood pressure was obtained using a semi-automated computer-controlled device. Arterial tonometry and simultaneous electrocardiography (ECG) were obtained from the brachial, radial, femoral, and carotid arteries using a custom transducer. Body surface measurements were assessed from suprasternal notch to brachial, radial, femoral, and carotid recording sites. All data were digitized during the primary acquisition (ECG and to- nometry pressures at $1,000 \mathrm{~Hz}$ and audio at $12 \mathrm{kHz}$ ), and transferred to the core laboratory (Cardiovascular Engineering, Inc., Norwood, Mass., USA) for analysis by trained analysts who were blinded to clinical characteristics of the participants. Tonometry waveforms were signal-averaged with the ECG used as a fiducial point. Blood pressures were over-read in the core laboratory. Systolic and diastolic cuff pressures were used to calibrate the peak and trough of the signal-averaged brachial pressure waveform. Diastolic and integrated mean brachial pressures were used to calibrate carotid pressure tracings [31]. Carotid-femoral pulse wave velocity (CFPWV) was calculated from tonometry waveforms, and body surface measurements were corrected for parallel transmission as described previously [12]. CFPWV and carotid pulse pressure (CPP) were used as the primary measures because they are the most robust and reproducible measurements and have been associated with increased risk of cardiovascular events and decreased survival in ESRD [32-40].

\section{Kidney Measures}

Estimated glomerular filtration rate (eGFR) was calculated using the CKD-EPI 2012 equation based on the combination of serum creatinine and cystatin C [41]. This eGFR equation was used rather than equations based on creatinine or cystatin $\mathrm{C}$ alone because the combination has been shown to provide a more accurate and precise estimate of measured GFR [41-44]. Serum creatinine assays were performed at the Icelandic Heart Association using the Roche-Hitachi P-module instrument with Creatininase Plus assay (CV 2.3\%) and calibrated to isotope dilution mass spectrometry reference materials at the University of Minnesota. Serum cystatin $\mathrm{C}$ assays were performed at the University of Minnesota using a particle-enhanced immune-nephelometric assay (PENIA, CV 2.7\%) and standardized to International Federation for Clinical Chemists reference materials [45].

Albuminuria was assessed from a spot urine albumin-creatinine ratio (ACR) $[46,47]$. Urine albumin and creatinine assays were performed at the Icelandic Heart Association using Tinaquant immunoturbimetric assay and HiCo Creatinine Jaffe method assay, respectively (CVs 7.2 and $4.2 \%$, respectively), and calibrated to reference materials at the University of Minnesota.

CKD was defined as eGFR $<60 \mathrm{ml} / \mathrm{min} / 1.73 \mathrm{~m}^{2}$ or ACR $>30$ $\mathrm{mg} / \mathrm{g}$. GFR $<30 \mathrm{ml} / \mathrm{min} / 1.73 \mathrm{~m}^{2}$ and ACR $>300 \mathrm{mg} / \mathrm{g}$ were considered severe abnormalities.

\section{Covariate Definitions}

Hypertension was self-reported, defined as responding 'yes' to the question 'Has a doctor or a health provider ever told you that you had high blood pressure or hypertension?' Diabetes was defined by self-report, fasting glucose, or medication use. Hyperlipidemia was defined as being on treatment for high cholesterol. Coronary artery disease (CAD) was defined by ICD codes for myocardial infarction and its sequelae, ischemic heart disease, coronary aneurysm or dissection, and atherosclerosis.

\section{Statistical Analysis}

Data was summarized with descriptive statistics including means, standard deviations (SD), ranges, $p$ values, and 95\% confidence intervals (CI). Albuminuria was described with median and interquartile ranges. Due to skewed data, albuminuria and CFPWV were expressed using the natural logarithm and negative inverse transformations, respectively. Associations were analyzed by stan- 
dard deviation of the independent variables, inverse CFPWV (iCFPWV) and CPP.

Graphical modeling (scatter plots) was used to assess crude associations. The association between kidney measures and aortic stiffness was examined using linear regression, with assessment for non-linear relationships. Based on graphical modeling, the relationship between eGFR and CPP appeared to be nonlinear with an apparent threshold at $85 \mathrm{~mm} \mathrm{Hg}$. A piecewise model with a threshold at $85 \mathrm{~mm} \mathrm{Hg}$ of CPP was found to be a better fit by ANOVA and likelihood ratio tests when compared to linear or spline models and, therefore, was used for subsequent models (online suppl. table 1). Bivariate models were performed and covariates with $\mathrm{p}$ value of less than 0.2 were eligible for a multivariable model in addition to covariates stated a priori. Sequential sets of multivariable models were created to explore the impact of demographic parameters (age, sex, heart rate, height) and CVD risk factors (hemoglobin A1c, C-reactive protein, high-density lipoprotein cholesterol, mean arterial blood pressure) on the associations. Heart rate and height were included in these models, as they influence the tonometry protocol. Various blood pressure measurements were explored, including systolic blood pressure (SBP), diastolic blood pressure (DBP), peripheral pulse pressure (PPP), and mean arterial pressure (MAP). MAP was used in the final models to reduce issues of colinearity. We preferred the use of continuous covariates in the multivariable models to avoid underestimation of confounding variables. We did sensitivity analyses examining the impact of additional clinical variables on model results. A p value $<0.05$ was considered statistically significant. Statistical analyses were done in $\mathrm{R}$ version 3.1.0 [48].

\section{Ethics}

AGES-RS was approved by the National Bioethics Committee in Iceland (VSN-00-063) and by the National Institute on Aging Intramural Institutional Review Board. Our investigation of aortic stiffness, kidney function, and aging in the AGES-RS cohort was approved by the Institutional Review Board of Tufts Medical Center (IRB \#9222). All participants gave written informed consent.

\section{Results}

\section{Description of the Sample}

This older population (range 69-96 years) had a high prevalence of hypertension and low prevalence of diabetes (table 1). eGFR was lower and ACR was higher in older participants. A total of $28.3 \%$ had eGFR $<60 \mathrm{ml} /$ $\mathrm{min} / 1.73 \mathrm{~m}^{2}, 8.0 \%$ had ACR $>30 \mathrm{mg} / \mathrm{g}$, and $32.0 \% \mathrm{had}$ $\mathrm{CKD}$. The prevalence of CKD was significantly higher in older age categories. Only $1.8 \%$ of participants had eGFR $<30 \mathrm{ml} / \mathrm{min} / 1.73 \mathrm{~m}^{2}$ and less than $1 \%$ had ACR $>300 \mathrm{mg} / \mathrm{g}$. eGFR and ACR were weakly correlated $(\mathrm{r}=$ $-0.22)$.

Mean (SD) CFPWV was $12.9(4.2) \mathrm{m} / \mathrm{s}$ and mean (SD) $\mathrm{CPP}$ was 69 (21) $\mathrm{mm} \mathrm{Hg}$ (online suppl. fig. 2). Both measures of aortic stiffness were higher in older participants (table 1 and online suppl. fig. 3). CPP was highly corre- lated with SBP and PPP $(r=0.83$ and $r=0.93$, respectively), but had a weaker correlation with MAP and no correlation with DBP $(r=0.53$ and $r=-0.07$, respectively) (online suppl. table 2). CFPWV was more weakly correlated with peripheral blood pressure measurements $(\mathrm{r}=$ $0.40, r=0.21, r=0.36$, and $r=0.32$ for SBP, DBP, MAP, and $\mathrm{PPP}$, respectively). CFPWV and CPP were not strongly correlated with each other $(r=0.29)$.

\section{Association of Aortic Stiffness with eGFR}

There was wide variability in the relationships between aortic stiffness measures and eGFR, with an apparent non-linear relationship for CPP and linear relationship with CFPWV (fig. 1). For CPP less than or equal to $85 \mathrm{~mm}$ $\mathrm{Hg}$ (79\% of the sample), there was no association of CPP and eGFR in both unadjusted and adjusted models. Conversely, for CPP greater than $85 \mathrm{~mm} \mathrm{Hg}$ ( $21 \%$ of the sample), a higher CPP was associated with a lower eGFR in the unadjusted model (fig. 1 and table 2). The association was attenuated after adjusting for age and further diminished after adjustments for CVD risk factors and ACR were made. Although higher CFPWV was associated with lower eGFR in the unadjusted model, this association was attenuated after adjustment. There was no interaction between iCFPWV or CPP and age $(\mathrm{p}=0.61$ and $\mathrm{p}=0.24$, respectively). In sensitivity analyses, relationships were slightly stronger with eGFR based on serum creatinine than on serum cystatin $\mathrm{C}$ alone and intermediate with eGFR based on both filtration markers (online suppl. table 3).

\section{Association of Aortic Stiffness with Urine ACR}

There was a wide variability in the relationships between aortic stiffness measures and ACR, with an apparent linear relationship for both CPP and CFPWV (fig. 1). Higher CPP was associated with higher levels of albuminuria in the unadjusted model and the association remained significant even in the fully adjusted model (a $14 \%$ higher ACR per SD higher CPP) (table 3). A higher CFPWV was associated with higher levels of albuminuria in the unadjusted model, but the association was attenuated after adjustment.

\section{Sensitivity Analyses}

There were no substantive differences in effect sizes for the associations of CPP or CFPWV and eGFR when smoking status, diabetic status, statin use, treatment for hypertension, or different cholesterol measures were included in multivariable models (online suppl. table 4). All final models remained nonsignificant. The association of 
Table 1. Clinical characteristics by age

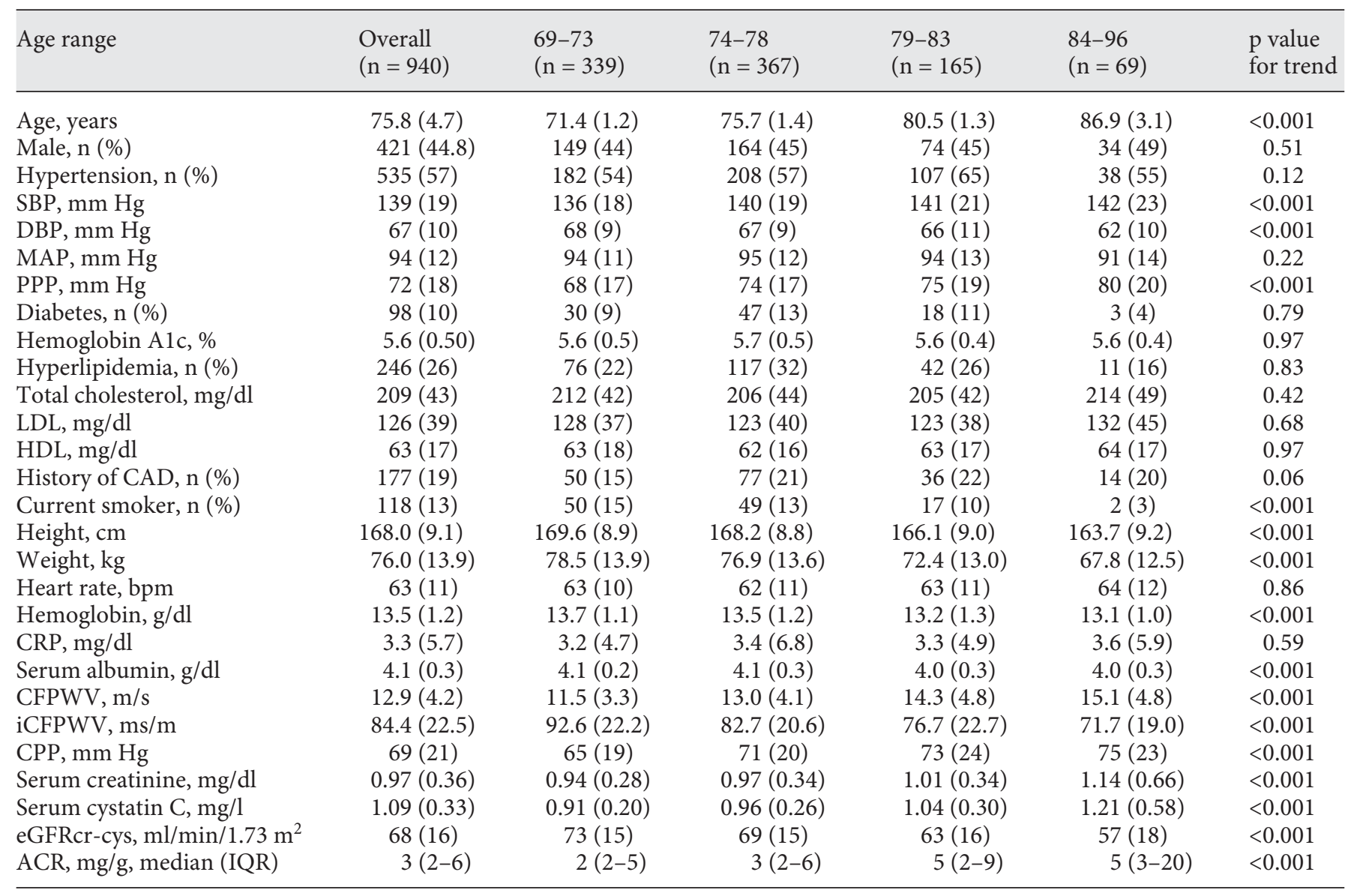

For descriptive purposes, age categories are uniform ( 4 years) except the oldest category. LDL $=$ Low-density lipoprotein; HDL $=$ high-density lipoprotein; eGFRcr-cys = estimated glomerular filtration rate based on creatinine and cystatin C.

$\mathrm{CPP}$ and ACR was attenuated by the inclusion of statin use, but not other variables (online suppl. table 5; $\beta$ (95\% $\mathrm{CI})=0.11(-0.01,0.24) \mathrm{ln} \mathrm{mg} / \mathrm{g}$ per SD). The association of CFPWV and ACR was not attenuated after inclusion of these additional risk factors (online suppl. table 5). Relationships between PPP and both eGFR and ACR were similar to relationships of CPP to eGFR and ACR (online suppl. table 6).

\section{Discussion}

CKD affects a large segment of the aging population, but the causes remain poorly defined. The transmission of higher pressure and flow pulsatility into the kidney microvasculature due to increased aortic stiffness is a potential mechanism of disease. In a population-based study of
940 older adults, we found a prevalence of CKD of $32 \%$ and a broad range of values of CFPWV and CPP. We found that CPP was more strongly related to kidney disease measures than CFPWV, but both measures were attenuated after adjustments for age and CVD risk factors. A higher CPP was associated with modestly higher levels of albuminuria after adjustments, suggesting that aortic stiffness may play a role in the development of kidney disease.

The ranges of CFPWV and CPP seen in our study were similar to those seen in other older populations [24,49]. The average values in our study were higher than those seen in younger cohorts from both the general population, such as the Framingham Study which used the same protocol and equipment, as well as CKD populations, such as the Chronic Renal Insufficiency Cohort Study $[18,21]$. The observed measures for aortic stiffness in our 
Table 2. Multivariable linear regression of measures of aortic stiffness and eGFR $\left(\mathrm{ml} / \mathrm{min} / 1.73 \mathrm{~m}^{2}\right)$

\begin{tabular}{|c|c|c|c|c|c|c|c|c|}
\hline & \multicolumn{2}{|c|}{$\mathrm{CPP} \leq 85 \mathrm{~mm} \mathrm{Hg}(\mathrm{n}=743)$} & \multicolumn{3}{|c|}{$\mathrm{CPP}>85 \mathrm{~mm} \mathrm{Hg}(\mathrm{n}=197)$} & \multicolumn{3}{|l|}{ CFPWV $^{\mathrm{a}}$} \\
\hline & $\begin{array}{l}\triangle \text { in eGFR per } \\
\text { SD of CPP }\end{array}$ & $95 \% \mathrm{CI}$ & $\begin{array}{l}\triangle \text { in eGFR per } \\
\text { SD of CPP }\end{array}$ & $95 \% \mathrm{CI}$ & $\mathrm{R}^{2}$ & $\begin{array}{l}\Delta \text { in eGFR per } \\
\text { SD of CFPWV }\end{array}$ & $95 \% \mathrm{CI}$ & $\mathrm{R}^{2}$ \\
\hline Model 1 & -0.26 & $-1.85,1.33$ & -4.54 & $-8.30,-0.78$ & 0.018 & -1.87 & $-2.89,-0.85$ & 0.014 \\
\hline Model 2 & 0.19 & $-1.44,1.83$ & -4.68 & $-8.44,-0.93$ & 0.026 & -2.26 & $-3.31,-1.21$ & 0.032 \\
\hline Model 3 & 0.65 & $-0.92,2.21$ & -3.51 & $-7.10,0.08$ & 0.112 & -0.7 & $-1.76,0.36$ & 0.11 \\
\hline Model 4 & -0.28 & $-2.05,1.48$ & -3.25 & $-6.84,0.34$ & 0.117 & -1.2 & $-2.37,-0.04$ & 0.114 \\
\hline Model 5 & -0.41 & $-2.14,1.33$ & -2.38 & $-5.89,1.14$ & 0.166 & -0.33 & $-1.49,0.84$ & 0.161 \\
\hline Model 6 & -0.03 & $-1.77,1.72$ & -2.72 & $-6.23,0.79$ & 0.178 & -0.29 & $-1.46,0.87$ & 0.174 \\
\hline
\end{tabular}

Model 1: unadjusted. Model 2: model $1+$ sex, heart rate, height. Model 3: model $2+$ age. Model 4: model $3+$ MAP. Model 5: model 4 + HDL cholesterol, HbA1c, CRP. Model 6: model 5 + ln ACR.

Effect sizes and confidence intervals are expressed per SD of the independent variable, iCFPWV or CPP.

eGFR = Estimated glomerular filtration rate based on creatinine and cystatin C; HDL = high-density lipoprotein; HgbA1c = hemoglobin A1c; $\mathrm{CRP}=\mathrm{C}$-reactive protein; $\ln \mathrm{ACR}$ = natural logarithm of urine ACR ratio.

${ }^{a}$ CFPWV modeled as the negative inverse.

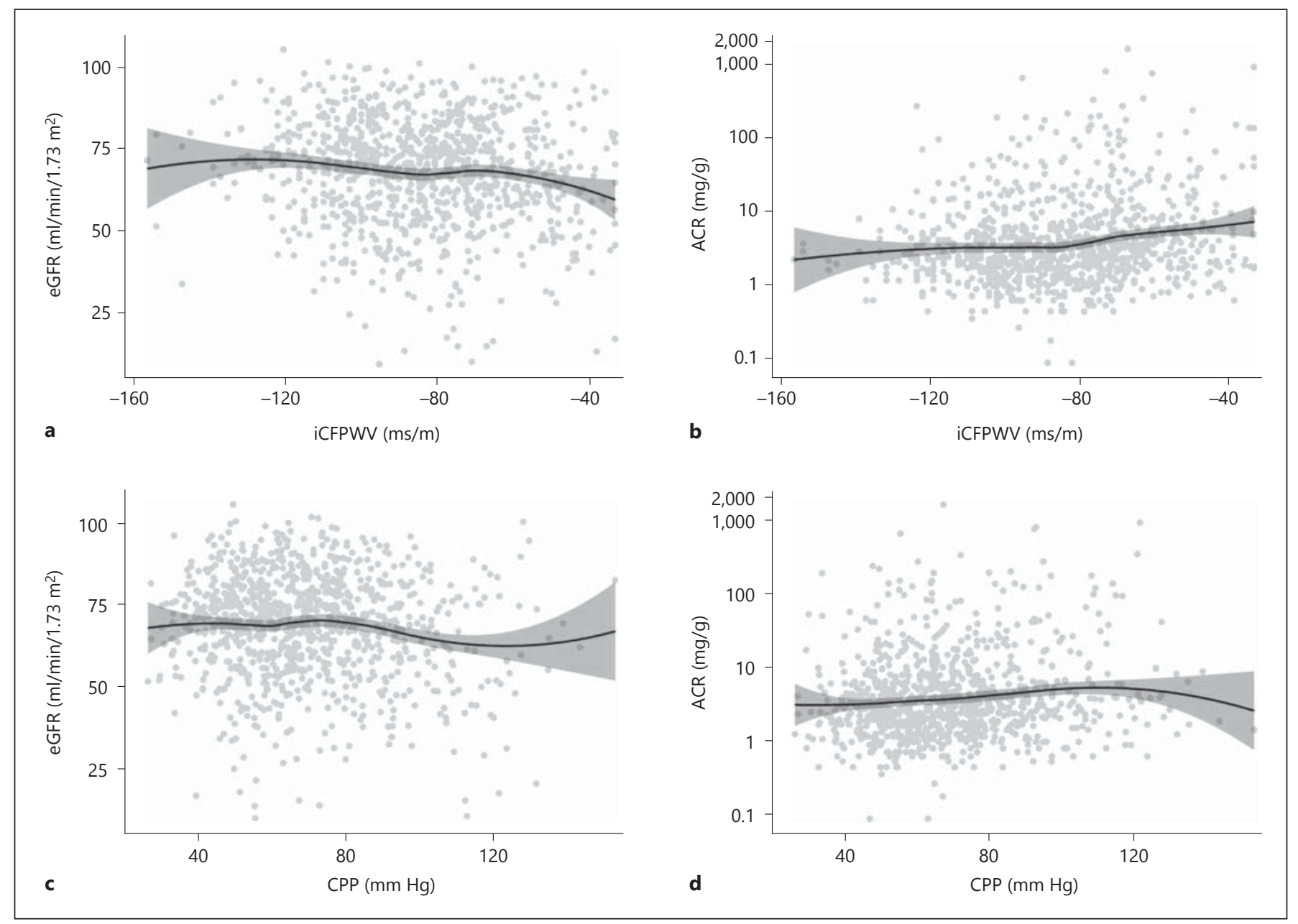

Fig. 1. Relationship of aortic stiffness with kidney measures. a Relationship of iCFPWV on eGFR. b Relationship of iCFPWV on ACR. c Relationship of CPP on eGFR. d Relationship of CPP on ACR. 
Table 3. Multivariable linear regression of measures of aortic stiffness and albuminuria

\begin{tabular}{|c|c|c|c|c|c|c|}
\hline & \multicolumn{3}{|l|}{ СРP } & \multicolumn{3}{|l|}{ CFPWV $^{\mathrm{a}}$} \\
\hline & $\begin{array}{l}\triangle \text { in } \ln A C R \text { per } \\
S D \text { of } C P P\end{array}$ & $95 \%$ CI & $\mathrm{R}^{2}$ & $\begin{array}{l}\triangle \text { in } \ln A C R \text { per } \\
S D \text { of CFPWV }\end{array}$ & $95 \% \mathrm{CI}$ & $\mathrm{R}^{2}$ \\
\hline Model 1 & 0.16 & $0.08,0.25$ & 0.015 & 0.21 & $0.12,0.29$ & 0.025 \\
\hline Model 2 & 0.23 & $0.14,0.32$ & 0.061 & 0.17 & $0.08,0.25$ & 0.049 \\
\hline Model 3 & 0.19 & $0.10,0.28$ & 0.089 & 0.09 & $0.001,0.18$ & 0.075 \\
\hline Model 4 & 0.17 & $0.06,0.28$ & 0.089 & 0.05 & $-0.05,0.14$ & 0.080 \\
\hline Model 5 & 0.15 & $0.04,0.26$ & 0.105 & 0.01 & $-0.09,0.11$ & 0.098 \\
\hline Model 6 & 0.14 & $0.03,0.24$ & 0.118 & 0.01 & $-0.09,0.11$ & 0.112 \\
\hline
\end{tabular}

Model 1: unadjusted. Model 2: model $1+$ sex, heart rate, height. Model 3: model $2+$ age. Model 4: model $3+$ MAP. Model 5: model $4+$ HDL cholesterol, HgbA1c, CRP. Model 6: model $5+$ eGFR.

Effect sizes and confidence intervals are expressed per SD of the independent variable, iCFPWV or ACR.

ln ACR = Natural logarithm of urine ACR ratio; iCFPWV = inverse carotid femoral pulse wave velocity; $\mathrm{HDL}=$ high-density lipoprotein; HgbA1c = hemoglobin A1c; CRP = C-reactive protein; eGFR = estimated glomerular filtration rate based on creatinine and cystatin C.

a ACR modeled as natural logarithm, CFPWV modeled as negative inverse.

population included values that have previously been associated with increased risk of cardiovascular events [32]. However, the strength of the association of the aortic stiffness and cardiovascular events may attenuate with age [50].

Although CFPWV and CPP are both used as measures of aortic stiffness, we found these parameters to have different relationships to the kidney disease measures, especially ACR. CFPWV is computed based on the distance from the carotid to femoral sites over transit time between the end of diastole at the two sites; it is primarily affected by the blood vessel wall properties, such as thickness and elasticity [39]. These changes in wall properties can lead to loss of impedance mismatch between the central and peripheral vasculature, resulting in increased transmission of pulsatility into the peripheral arterial beds, such as the kidneys. Although we did not observe this relationship in our study, the higher pressure and flow pulsatility in the kidney are hypothesized to produce vasoconstriction and reduced GFR. On the other hand, CPP is affected by cardiac function, pulsatility of blood flow, and the interaction between aortic stiffness and aortic diameter [51]. Excessive pressure pulsatility associated with increased CPP may damage the endothelium of the glomerular capillaries, potentially contributing to albuminuria [9]. The majority of previous studies examining aortic stiffness and albuminuria have used CFPWV or PWV at other sites, such as aortic or brachial-femoral, as the measure of aortic stiffness.

Aortic Stiffness and Kidney Disease
We found no evidence for a relationship between eGFR and either measure of aortic stiffness. The narrow confidence intervals for the relationship of eGFR with iCFPWV $\left(-1.46\right.$ to $+0.87 \mathrm{ml} / \mathrm{min} / 1.73 \mathrm{~m}^{2}$ per SD of iCFPWV) and CPP ( -6.23 to $+0.79 \mathrm{ml} / \mathrm{min} / 1.73 \mathrm{~m}^{2}$ per $\mathrm{SD}$ of $\mathrm{CPP}$ ) make it unlikely that there is a clinically meaningful association in our study population. However, our study population might not have been optimal to detect the associations. Due to the age of our participants, those who had died prior to the AGES-RS-I visit or those who had declined participation may have been more likely to have higher aortic stiffness or lower kidney function, resulting in the underestimation of the true relationship. This type of informative censoring would bias our findings toward the null hypothesis. Although our measures of aortic stiffness and kidney disease are based on state of-the-art technology, they may be imprecise, presenting another possible source of bias toward the null hypothesis. For example, eGFR is known to provide an imprecise estimate of measured GFR, due to non-GFR determinants of circulating levels of creatinine and cystatin C, with eGFR based on both creatinine and cystatin $\mathrm{C}$ to be more precise than either of them alone [52]. Our colleagues found a significant relationship between measured GFR and CFPWV in a selected cohort from a later visit of the AGES study [29]. The differences in the relationship of aortic stiffness to measured and eGFR serve to highlight potential limitations of eGFR for these analyses, a finding that has been shown in previous studies [53]. 
The observed absence of a strong relationship between eGFR and aortic stiffness is consistent with findings from two other population-based studies with both cross-sectional and longitudinal components, the Health $\mathrm{ABC}$ and Framingham Heart Studies [20, 21]. However, other studies in the general population as well as CKD cohorts found significant associations between aortic stiffness and lower eGFR in cross-sectional and longitudinal studies $[18,20,22,23,26]$, even after adjustment for age, blood pressure, and CVD risk factors. These associations were often seen in younger populations, minimizing the potential effect of survivor bias affecting our population.

We did find a significant association between aortic stiffness measured with CPP, but not CFPWV, and albuminuria, even after adjustment for age, sex, MAP, and other CVD risk factors. Our observed relationship with CPP and albuminuria, but not eGFR, may be due to the different mechanisms leading to increased albuminuria vs. lower eGFR. However, the strength of the association of CPP with albuminuria was modest (a 14\% higher ACR per SD higher CPP). The effect of a higher CPP on the development of kidney disease (ACR $>30 \mathrm{mg} / \mathrm{g}$ ) and its progression needs to be further explored with longitudinal follow-up. Meanwhile, the narrow confidence intervals for the relationship of ACR to CFPWV (-0.09 to 0.11 $\mathrm{mg} / \mathrm{g}$ per SD of CFPWV) suggest that it is highly unlikely that there is a clinically meaningful association in the participants of our study.

Our finding of the association of CPP and albuminuria is consistent with the Framingham Heart Study in which CPP and CFPWV at baseline were associated with baseline albuminuria in cross-sectional analyses and incident albuminuria during longitudinal follow-up in age- and gender-adjusted models. However, the longitudinal association was attenuated and became nonsignificant after adjustment for baseline blood pressure and other CVD risk factors [21]. However, other studies have shown significant relationships between CFPWV and albuminuria [54-60]. The largest of the prior studies, CRIC and the Renal Risk in Derby studies, were crosssectional analyses of patients with CKD and may represent changes already present in those with reduced kidney function $[54,56]$.

The associations of measures of aortic stiffness and kidney disease measures in our study are significantly confounded by age. We observed strong relationships between age and measures of aortic stiffness and kidney disease. Aging is associated with decreased elasticity, decreased compliance, and increased vessel wall thickness, potentially resulting in both aortic stiffness and reduced
GFR and albuminuria [5, 6, 8-12]. Because there are numerous changes that occur with age, many of which may be unmeasured, and because age precedes our outcomes of interest, it was found that age introduces confounding by baseline conditions as well as potential mechanisms along the causal pathway. Unfortunately, it is impossible to clarify these complicated relationships with the crosssectional design of our study.

Our study had several strengths. First, the study design is a population-based cohort that is representative of the Icelandic population at large. Second, the relatively large sample size provides sufficient power to examine even modest associations. The aortic tonometry protocol, including CFPWV and CPP, is highly standardized and has high correlation coefficients for reproducibility [9]. Additionally, the ascertainment of kidney disease included both ACR, a measure of kidney damage, as well as eGFR based on the combination of creatinine and cystatin C, which has been shown to be more accurate and precise compared to either of them alone as a measure of kidney function.

Our study also had several limitations. First, the population of Iceland is Caucasian; therefore, our findings cannot be applied to other races or ethnicities. However, the homogeneity of the population may allow a more accurate assessment of the true relationship between aortic stiffness and kidney disease. Survivor bias and regression dilution are introduced with the older age of the study population. Additionally, we have used eGFR instead of measured GFR as the primary measure for kidney function. Although measured GFR would provide the true quantification of kidney function, the eGFR is used more often in the clinical setting and is more practical. Lastly, this is a cross-sectional study and the direction of causality cannot be determined. Previous studies have suggested that baseline aortic stiffness is associated with subsequent changes in kidney function, although the relationship could be bidirectional [23]. The longitudinal nature of these associations should be more thoroughly explored to make any causal inferences.

In conclusion, aortic stiffness measured with CPP was related to albuminuria in a representative elderly Icelandic population; higher CPP was associated with higher levels of albuminuria, independent of age and CVD risk factors. CPP was not independently associated with lower eGFR. In contrast to previous literature, CFPWV was not associated with higher albuminuria or lower eGFR. However, the association of aortic stiffness to eGFR may be confounded by age and CVD risk factors, making it difficult to delineate the mechanisms of disease. Future 
studies are needed to explore the mechanisms underlying $\mathrm{CKD}$; also better markers of vascular and kidney disease have to be identified.

\section{Acknowledgments}

This study was supported by a grant from National Institutes of Health (R01 DK082447), contract from the National Institute on Aging (N01-AG-1-2100), Hjartavernd (the Icelandic Heart Association) and the Icelandic Parliament (Althingi). The funding sources were not required to approve publication of the finished manuscript. Dr. Aghogho Okparavero assisted with manuscript preparation.

Preliminary results of this research will be presented in abstract form at the Annual Meeting of the American Society of Nephrology, November 15, 2014, Philadelphia, Pa., USA.

\section{Disclosure Statement}

Gary F. Mitchell is owner of Cardiovascular Engineering, Inc., a company that develops and manufactures devices to measure vascular stiffness; he serves as a consultant to and receives honoraria from Novartis and Merck, and is funded by research grants from the National Institutes of Health.

Andrew S. Levey reports funding to Tufts Medical Center for research and contracts with the National Institutes of Health, National Kidney Foundation, Amgen, Pharmalink AB and Gilead Sciences, and a patent pending for novel metabolites to estimate GFR. Provisional patent (Coresh, Inker and Levey) was filed August 15, 2014: precise estimation of GFR from multiple biomarkers (licensing under negotiations).

Tamara Harris works for the National Institute on Aging (NIA).

Margret B. Andresdottir, Vilmundur Gudnason, Runolfur Palsson, Farzad Noubary, Naya Huang and Katherine H. Michener have none to declare.

\section{References}

1 Coresh J, Selvin E, Stevens LA, Manzi J, Kusek JW, Eggers P, Van Lente F, Levey AS: Prevalence of chronic kidney disease in the United States. JAMA 2007;298:2038-2047.

2 Collins AJ, Chen SC, Gilbertson DT, Foley $\mathrm{RN}$ : CKD surveillance using administrative data: impact on the health care system. Am J Kidney Dis 2009;53(3 suppl 3):S27-S36.

3 Laliberté F, Bookhart BK, Vekeman F, Corral M, Duh MS, Bailey RA, Piech CT, Lefebvre P: Direct all-cause health care costs associated with chronic kidney disease in patients with diabetes and hypertension: a managed care perspective. J Manag Care Pharm 2009;15: 312-322.

4 Zhang QL, Rothenbacher D: Prevalence of chronic kidney disease in population-based studies: systematic review. BMC Public Health $2008 ; 8: 117$.

5 Lindeman RD, Tobin J, Shock NW: Longitudinal studies on the rate of decline in renal function with age. J Am Geriatr Soc 1985;33: 278-285.

6 Davies DF, Shock NW: Age changes in glomerular filtration rate, effective renal plasma flow, and tubular excretory capacity in adult males. J Clin Invest 1950;29:496-507.

7 McLachlan M, Wasserman P: Changes in sizes and distensibility of the aging kidney. Br J Radiol 1981;54:488-491.

8 Garg AX, Kiberd BA, Clark WF, Haynes RB, Clase CM: Albuminuria and renal insufficiency prevalence guides population screening: results from the NHANES III. Kidney Int 2002;61:2165-2175.

9 Mitchell GF: Effects of central arterial aging on the structure and function of the peripheral vasculature: implications for end-organ damage. J Appl Physiol (1985) 2008;105: 1652-1660.

10 Nichols WW, O'Rourke MF: Mcdonald's Blood Flow in Arteries: Theoretical, Experi- mental, and Clinical Principles, ed 4. London, Oxford University Press, 1998.

11 Benetos A, Laurent S, Hoeks AP, Boutouyrie $\mathrm{PH}$, Safar ME: Arterial alterations with aging and high blood pressure. A noninvasive study of carotid and femoral arteries. Arterioscler Thromb 1993;13:90-97.

12 Mitchell GF, Parise H, Benjamin EJ, Larson MG, Keyes MJ, Vita JA, Vasan RS, Levy D: Changes in arterial stiffness and wave reflection with advancing age in healthy men and women: the Framingham heart study. Hypertension 2004;43:1239-1245.

13 O’Rourke MF, Safar ME: Relationship between aortic stiffening and microvascular disease in brain and kidney: cause and logic of therapy. Hypertension 2005;46:200-204.

14 Ilyas B, Dhaun N, Markie D, Stansell P, Goddard J, Newby DE, Webb DJ: Renal function is associated with arterial stiffness and predicts outcome in patients with coronary artery disease. QJM 2009;102:183-191.

15 Wang MC, Tsai WC, Chen JY, Huang JJ: Stepwise increase in arterial stiffness corresponding with the stages of chronic kidney disease. Am J Kidney Dis 2005;45:494-501.

16 Takenaka T, Mimura T, Kanno Y, Suzuki H: Qualification of arterial stiffness as a risk factor to the progression of chronic kidney diseases. Am J Nephrol 2005;25:417-424.

17 Mourad JJ, Pannier B, Blacher J, Rudnichi A, Benetos A, London GM, Safar ME: Creatinine clearance, pulse wave velocity, carotid compliance and essential hypertension. Kidney Int 2001;59:1834-1841.

18 Townsend RR, Wimmer NJ, Chirinos JA, Parsa A, Weir M, Perumal K, Lash JP, Chen J, Steigerwalt SP, Flack J, Go AS, Rafey M, Rahman M, Sheridan A, Gadegbeku CA, Robinson NA, Joffe M: Aortic PWV in chronic kidney disease: a CRIC ancillary study. Am J Hypertens 2010;23:282-289.
19 Ford ML, Tomlinson LA, Chapman TP, Rajkumar C, Holt SG: Aortic stiffness is independently associated with rate of renal function decline in chronic kidney disease stages 3 and 4. Hypertension 2010;55:1110-1115.

20 Madero M, Peralta C, Katz R, Canada R, Fried L, Najjar S, Shlipak M, Simonsick E, Lakatta E, Patel K, Rifkin D, Hawkins M, Newman A, Sarnak M: Association of arterial rigidity with incident kidney disease and kidney function decline: the health ABC study. Clin J Am Soc Nephrol 2013;8:424-433.

21 Upadhyay A, Hwang SJ, Mitchell GF, Vasan RS, Vita JA, Stantchev PI, Meigs JB, Larson MG, Levy D, Benjamin EJ, Fox CS: Arterial stiffness in mild-to-moderate CKD. J Am Soc Nephrol 2009;20:2044-2053.

22 Peralta CA, Jacobs DR Jr, Katz R, Ix JH, Madero M, Duprez DA, Sarnak MJ, Criqui MH, Kramer HJ, Palmas W, Herrington D, Shlipak MG: Association of pulse pressure, arterial elasticity, and endothelial function with kidney function decline among adults with estimated GFR $>60 \mathrm{ml} / \mathrm{min} / 1.73 \mathrm{~m}(2)$ : the multiethnic study of atherosclerosis (MESA). Am J Kidney Dis 2012;59:41-49.

23 Tomiyama $\mathrm{H}$, Tanaka $\mathrm{H}$, Hashimoto $\mathrm{H}$, Matsumoto C, Odaira $M$, Yamada J, Yoshida $M$, Shiina K, Nagata M, Yamashina A: Arterial stiffness and declines in individuals with normal renal function/early chronic kidney disease. Atherosclerosis 2010;212:345-350.

24 Madero M, Wassel CL, Peralta CA, Najjar SS, Sutton-Tyrrell K, Fried L, Canada R, Newman A, Shlipak MG, Sarnak MJ: Cystatin C associates with arterial stiffness in older adults. J Am Soc Nephrol 2009;20:1086-1093.

25 Briet M, Collin C, Karras A, Laurent S, Bozec E, Jacquot C, Stengel B, Houillier P, Froissart M, Boutouyrie P: Arterial remodeling associates with CKD progression. J Am Soc Nephrol 2011;22:967-974. 
26 Yoshida M, Tomiyama H, Yamada J, Koji Y, Shiina K, Nagata M, Yamashina A: Relationships among renal function loss within the normal to mildly impaired range, arterial stiffness, inflammation, and oxidative stress. Clin J Am Soc Nephrol 2007;2:1118-1124.

27 Hermans MM, Henry R, Dekker JM, Kooman JP, Kostense PJ, Nijpels G, Heine RJ, Stehouwer $\mathrm{CD}$ : Estimated glomerular filtration rate and urinary albumin excretion are independently associated with greater arterial stiffness: the Hoorn study. J Am Soc Nephrol 2007;18:1942-1952.

28 Taal MW, Sigrist MK, Fakis A, Fluck RJ, McIntyre CW: Markers of arterial stiffness are risk factors for progression to end-stage renal disease among patients with chronic kidney disease stages 4 and 5. Nephron Clin Pract 2007;107:c177-c181.

29 Woodard T, Sigurdsson S, Gotal JD, Torjesen AA, Inker LA, Aspelund T, Eiriksdottir G, Gudnason V, Harris TB, Launer LJ, Levey AS, Mitchell GF: Mediation analysis of aortic stiffness and renal microvascular function. J Am Soc Nephrol 2015;26:1181-1187.

30 Harris TB, Launer LJ, Eiriksdottir G, Kjartansson O, Jonsson PV, Sigurdsson G, Thorgeirsson G, Aspelund T, Garcia ME, Cotch MF, Hoffman HJ, Gudnason V: Age, gene/ environment susceptibility-Reykjavik study: multidisciplinary applied phenomics. Am J Epidemiol 2007;165:1076-1087.

31 Kelly R, Fitchett D: Noninvasive determination of aortic input impedance and external left ventricular power output: a validation and repeatability study of a new technique. J Am Coll Cardiol 1992;20:952-963.

32 Mitchell GF, Hwang SJ, Vasan RS, Larson MG, Pencina MJ, Hamburg NM, Vita JA, Levy D, Benjamin EJ: Arterial stiffness and cardiovascular events: the Framingham heart study. Circulation 2010;121:505-511.

33 Mattace-Raso FU, van der Cammen TJ, Hofman A, van Popele NM, Bos ML, Schalekamp MA, Asmar R, Reneman RS, Hoeks AP, Breteler MM, Witteman JC: Arterial stiffness and risk of coronary heart disease and stroke: the Rotterdam study. Circulation 2006;113:657-663.

34 Sutton-Tyrrell K, Najjar SS, Boudreau RM, Venkitachalam L, Kupelian V, Simonsick EM, Havlik R, Lakatta EG, Spurgeon H, Kritchevsky S, Pahor M, Bauer D, Newman A: Elevated aortic pulse wave velocity, a marker of arterial stiffness, predicts cardiovascular events in well-functioning older adults. Circulation 2005;111:3384-3390.

35 Willum-Hansen T, Staessen JA, Torp-Pedersen C, Rasmussen S, Thijs L, Ibsen H, Jeppesen $\mathrm{J}$ : Prognostic value of aortic pulse wave velocity as index of arterial stiffness in the general population. Circulation 2006;113:664-670.

36 Blacher J, Guerin AP, Pannier B, Marchais SJ, Safar ME, London GM: Impact of aortic stiffness on survival in end-stage renal disease. Circulation 1999;99:2434-2439.

37 Guerin AP, Blacher J, Pannier B, Marchais SJ, Safar ME, London GM: Impact of aortic stiff- ness attenuation on survival of patients in end-stage renal failure. Circulation 2001;103: 987-992.

38 Pannier B, Guérin AP, Marchais SJ, Safar ME London GM: Stiffness of capacitive and conduit arteries: prognostic significance for endstage renal disease patients. Hypertension 2005; $45: 592-596$

39 Laurent S, Cockcroft J, Van Bortel L, Boutouyrie P, Giannattasio C, Hayoz D, Pannier B, Vlachopoulos C, Wilkinson I, Struijker-Boudier $\mathrm{H}$ : Expert consensus document on arterial stiffness: methodological issues and clinical applications. Eur Heart J 2006;27:2588-2605.

40 Boutouyrie P, Tropeano AI, Asmar R, Gautier I, Benetos A, Lacolley P, Laurent S: Aortic stiffness is an independent predictor of primary coronary events in hypertensive patients: a longitudinal study. Hypertension 2002;39:10-15.

41 Inker LA, Schmid CH, Tighiouart H, Eckfeldt JH, Feldman HI, Greene T, Kusek JW, Manzi J, Van Lente F, Zhang YL, Coresh J, Levey AS: Estimating glomerular filtration rate from serum creatinine and cystatin C. N Engl J Med 2012;367:20-29.

42 Schaeffner ES, Ebert N, Delanaye P, Frei U, Gaedeke J, Jakob O, Kuhlmann MK, Schuchardt M, Tölle M, Ziebig R, van der Giet M, Martus P: Two novel equations to estimate kidney function in persons aged 70 years or older. Ann Intern Med 2012;157:471-481.

43 Anderson AH, Yang W, Hsu CY, Joffe MM, Leonard MB, Xie D, Chen J, Greene T, Jaar BG, Kao P, Kusek JW, Landis JR, Lash JP, Townsend RR, Weir MR, Feldman HI: Estimating GFR among participants in the chronic renal insufficiency cohort (CRIC) study. Am J Kidney Dis 2012;60:250-261.

44 Teo BW, Xu H, Wang D, Li J, Sinha AK, Shuter B, Sethi S, Lee EJ: Estimating glomerular filtration rates by use of both cystatin $\mathrm{C}$ and standardized serum creatinine avoids ethnicity coefficients in Asian patients with chronic kidney disease. Clin Chem 2012;58:450-457.

45 Inker LA, Eckfeldt J, Levey AS, LeiendeckerFoster C, Rynders G, Manzi J, Waheed S, Coresh J: Expressing the CKD-EPI (chronic kidney disease epidemiology collaboration) cystatin C equations for estimating GFR with standardized serum cystatin C values. Am J Kidney Dis 2011;58:682-684.

46 Lamb EJ, MacKenzie F, Stevens PE: How should proteinuria be detected and measured? Ann Clin Biochem 2009;46:205-217.

47 McIntyre NJ, Taal MW: How to measure proteinuria? Curr Opin Nephrol Hypertens 2008; 17:600-603.

48 R Development Core Team: R: A Language and Environment for Statistical Computing. Vienna, Austria, R Foundation for Statistical Computing, 2014, http://www.R-project.org/.

49 Mitchell GF, Wang N, Palmisano JN, Larson MG, Hamburg NM, Vita JA, Levy D, Benjamin EJ, Vasan RS: Hemodynamic correlates of blood pressure across the adult age spectrum: noninvasive evaluation in the Framingham heart study. Circulation 2010;122:1379-1386.
50 Ben-Shlomo Y, Spears M, Boustred C, May M, Anderson SG, Benjamin EJ, Boutouyrie P, Cameron J, Chen CH, Cruickshank JK, Hwang SJ, Lakatta EG, Laurent S, Maldonado J, Mitchell GF, Najjar SS, Newman AB, Ohishi M, Pannier B, Pereira T, Vasan RS, Shokawa T, SuttonTyrell K, Verbeke F, Wang KL, Webb DJ, Willum Hansen T, Zoungas S, McEniery CM, Cockcroft JR, Wilkinson IB: Aortic pulse wave velocity improves cardiovascular event prediction: an individual participant meta-analysis of prospective observational data from 17,635 subjects. J Am Coll Cardiol 2014;63:636-646.

51 O’Rourke MF, Nichols WW, Safar ME: Pulse waveform analysis and arterial stiffness: realism can replace evangelism and scepticism. J Hypertens 2004;22:1633-1634; author reply 1634.

52 Fan L, Levey AS, Gudnason V, Eiriksdottir G, Andresdottir MB, Gudmundsdottir H, Indridason OS, Palsson R, Mitchell G, Inker LA: Comparing GFR estimating equations using cystatin $\mathrm{C}$ and creatinine in elderly individuals. J Am Soc Nephrol 2014;pii:ASN.2014060607.

53 Verhave JC, Fesler P, du Cailar G, Ribstein J, Safar ME, Mimran A: Elevated pulse pressure is associated with low renal function in elderly patients with isolated systolic hypertension. Hypertension 2005;45:586-591.

54 Weir MR, Townsend RR, Fink JC, Teal V, Anderson C, Appel L, Chen J, He J, Litbarg N, Ojo A, Rahman M, Rosen L, Sozio SM, Steigerwalt S, Strauss L, Joffe MM: Hemodynamic correlates of proteinuria in chronic kidney disease. Clin J Am Soc Nephrol 2011;6:2403-2410.

55 Smith A, Karalliedde J, De Angelis L, Goldsmith D, Viberti G: Aortic pulse wave velocity and albuminuria in patients with type 2 diabetes. J Am Soc Nephrol 2005;16:1069-1075.

56 McIntyre NJ, Fluck RJ, McIntyre CW, Fakis A, Taal MW: Determinants of arterial stiffness in chronic kidney disease stage 3. PLoS One 2013;8:e55444.

57 Bouchi R, Babazono T, Mugishima M, Yoshida N, Nyumura I, Toya K, Hanai K, Tanaka N, Ishii A, Uchigata Y, Iwamto Y: Arterial stiffness is associated with incident albuminuria and decreased glomerular filtration rate in type 2 diabetic patients. Diabetes Care 2011;34:2570-2575.

58 Yokoyama H, Aoki T, Imahori M, Kuramitsu M: Subclinical atherosclerosis is increased in type 2 diabetic patients with microalbuminuria evaluated by intima-media thickness and pulse wave velocity. Kidney Int 2004;66:448-454.

59 Munakata M, Nunokawa T, Yoshinaga K, Toyota T: Brachial-ankle pulse wave velocity is an independent risk factor for microalbuminuria in patients with essential hypertension - a Japanese trial on the prognostic implication of pulse wave velocity (J-TOPP). Hypertens Res 2006;29:515-521.

60 Kohara K, Tabara Y, Tachibana R, Nakura J, Miki T: Microalbuminuria and arterial stiffness in a general population: the Shimanami health promoting program (J-SHIPP) study. Hypertens Res 2004;27:471-477. 